\title{
Gênero e Brincadeira em Parquinhos Públicos de Salvador (BA) ${ }^{1}$
}

\author{
Carla Silva Fiaes \\ Reginalice de Lima Marques \\ Gabriela Souza Cotrim \\ Ilka Dias Bichara \\ Universidade Federal da Bahia
}

\begin{abstract}
RESUMO
Estudos sobre o uso do espaço para brincadeiras em ambientes abertos têm evidenciado que meninos e meninas apresentam diferenças nas brincadeiras, na preferência por determinados tipos de espaço e na forma de se organizar. Este trabalho se propõe a descrever e discutir as formas de uso do espaço em dois "parquinhos" na cidade de Salvador, priorizando os aspectos associados a como meninas e meninos os utilizam para brincar. Para tal foram realizadas sessões de observação, através de registro cursivo focal do evento de brincadeira e observação em varredura nos parques do Dique do Tororó e do Campo Grande. Não foram encontradas diferenças significativas na presença de meninos e meninas e as crianças brincaram predominantemente de brincadeiras de exercício físico, com diferenças de frequência na participação de grupos segregados e mistos. Constataram-se diferenças na ocupação do espaço relacionadas ao gênero e algumas delas associadas às dimensões dos espaços disponíveis e presença de adultos.
\end{abstract}

Palavras-chave: gênero; brincadeira; playground público.

\begin{abstract}
Gender and play in public playgrounds of Salvador (BA)

Studies about the use of space to play in open environments have shown that boys and girls show differences in play, preference for certain kinds of spaces and in how they organize themselves. This study proposes to describe and discuss ways to use space in two playgrounds in the city of Salvador, prioritizing the issues associated with how girls and boys use them to play. Sessions of observation were registered, through focus on cursive records of the event of play and scanning observations in Tororo's Dock and Campo Grande. There were no significant differences in the presence of boys and girls. Children played predominantly using physical exercise, with differences in the frequency of participation of segregated and mixed groups. Differences were found in the use of space based on gender, linked to the size of the available spaces and the adult's presence.
\end{abstract}

Keywords: gender; play; public playground.

Ao caminharmos pelas ruas das grandes metrópoles notamos vários fenômenos associados à presença de crianças nos espaços urbanos, uns claramente associados ao crescimento desordenado e a questões sociais de grande vulto, e outros inerentes a própria infância e associadas a questões desenvolvimentais. Quanto ao primeiro aspecto podemos destacar a transformação das ruas em local de moradia e/ou trabalho, inseguros e restritivos. Quanto ao segundo, podemos arrolar desde aspectos relativos à criatividade para acessar, apropriar e ressignificar esses espaços como, por exemplo, jogar bola em canteiros de avenidas e aquelas relativas a variáveis como gênero e idade. É sobre esse último aspecto que iremos lançar nosso olhar nesse artigo com o intuito de descrever e discutir algumas formas de apropriação e ressignificação do espaço urbano por crianças em uma metrópole, priorizando os aspectos associados a como meninas e meninos os utilizam para brincar.

Como na atualidade as ruas das grandes cidades se tornaram espaços de riscos para crianças em função do grande movimento de pessoas, veículos e ação da criminalidade, os adultos criaram parques, praças e outros locais destinados ao uso exclusivo de crianças, o que Rasmussen (2004) chamou de lugar para crianças (places for children). Em contrapartida, vemos 
que as crianças, principalmente as mais pobres, se apropriam de lugares não destinados a elas realizando adaptações nas brincadeiras, assim como também fazem usos criativos e até inusitados dos espaços e equipamentos transformando-os no que essa mesma autora chamou de lugar da criança (children's places). Ou seja, os lugares para crianças são aqueles planejados e disponibilizados pelos adultos enquanto os espaços das crianças são aqueles que elas próprias delimitam e delegam significados, muitas vezes diferentes daqueles para os quais foram construídos. Rasmussen (2004) ressalta que, nem sempre o lugar lúdico preparado por adultos corresponde àqueles preferidos pelas crianças para as suas brincadeiras, e que, quando isto acontece, estas podem escolher cenários bastante específicos, como uma árvore para a sua realização, demonstrando o seu caráter ativo frente às suas preferências e, com isso, um espaço 'para crianças' pode conter 'espaços da criança'.

Independentemente de se o lugar foi planejado ou não, estudos sobre o uso do espaço para brincadeiras em ambientes abertos têm evidenciado que meninos e meninas apresentam diferenças na preferência por determinadas áreas, se organizam geralmente de forma segregada e realizam brincadeiras diferentes (Archer, 1992; Aydt \& Corsaro, 2003; Beraldo, 1993; Martin $\&$ Fabes, 2001). Para Karsten (2003) os lugares usados pelas crianças são estruturados por gênero e muitas diferenças medeiam à utilização diferenciada de meninos e meninas. Em seu estudo, realizado em playgrounds públicos de Amsterdam, foi constatado que, comparativamente, os meninos usam mais os playgrounds que as meninas, além disso, eles também utilizam mais territórios amplos durante um maior espaço de tempo. Isso condiz com estudos anteriores como os de Levy, Taylor e Gelman (1995) e Harper e Sanders (1975), que constataram que meninos preferem espaços abertos e executam brincadeiras com muita movimentação, enquanto as meninas preferem ambientes internos ou delimitados e realizam brincadeiras mais concentradas.

Também outros dois fenômenos associados a gênero têm sido amplamente constatados e discutidos na literatura: a segregação por sexo dos grupos de brincantes e a estereotipia e a tipificação de gênero na escolha e desenvolvimento das brincadeiras (Bichara \& Carvalho, 2008). Beraldo (1993) relata que a preferência por brincar em grupos segregados e de brincadeiras consideradas como de meninas ou de meninos já é demonstrada aos três anos e que se mantém durante boa parte da idade escolar. Para Aydt e Corsaro
(2003) isto acontece porque a mais importante identidade que a criança aprende para definir a si mesma e aos outros é a de gênero. Essa é uma questão tão importante que crianças muito pequenas já identificam traços dessas diferenças. Poulin-Dubois, Serbin, Kenyon e Derbyshire (1994) relatam que crianças por volta dos sete meses de idade já reconhecem faces masculinas e femininas e que aos doze identificam de forma integrada faces e vozes masculinas e femininas. Ao fim do primeiro ano de idade já sabem diferenciar homens de mulheres, inclusive através de gravuras, e aos três já se reconhecem como menino ou menina (Maccoby, 1989).

O fenômeno da segregação por gênero tem sido amplamente constatado por estudos interculturais. Archer (1992) cita estudos realizados por autores diferentes e em várias partes do mundo onde esse fenômeno foi encontrado, como por exemplo, na Índia, em Okinawa, nas Filipinas, no México, no Quênia e nos Estados Unidos por Whiting e Edwards (1988), na China, em Bali, e também entre crianças Kung do Kalahari por Freedman (1980). Já no Brasil, a segregação foi encontrada entre os índios Parakanã (Gosso, 2005), em comunidades ribeirinhas pobres do estado de Sergipe, os índios Xocó e os descendentes de quilombolas do povoado Mocambo (Bichara, 2003), entre crianças frequentadoras de duas creches com níveis socioeconômicos distintos na cidade de São Paulo (Bichara, 1994) e na Ilha dos Frades na Baía de Todos os Santos (Seixas, 2007), entre outros.

Várias são as hipóteses explicativas para a segregação: como resultado de estímulos e reforçamentos advindos do contexto social no qual a criança vive; como resultado do desenvolvimento cognitivo, pois a criança necessitaria conviver entre pares para adquirir a identidade de pertencimento a um grupo social, ou seja, compreender e assumir o que é ser menino ou ser menina; ou como resultado também da compatibilidade de interesses entre crianças do mesmo sexo (Aydt $\&$ Corsaro, 2003). Sobre a hipótese da compatibilidade de interesses ou de estilo, Aydt e Corsaro (2003) argumentam que os grupos de brinquedo, segregados ou não, desenvolvem culturas diferentes. Sendo assim, grupos de meninos ou de meninas desenvolveriam culturas próprias diferenciando-se cada vez mais uns dos outros. Já Pellegrini (2004) considera que a diferença de estilos é consequência dos papéis reprodutivos diferenciados em que, por exemplo, os machos devem ser mais competitivos e assertivos. Esse autor também hipotetiza que diferenças biológicas no amadurecimento também podem explicar diferenças de atividade entre os sexos. 
Porém, é importante registrar que as crianças não brincam exclusivamente segregadas, grupos mistos são menos frequentes, porém não raros. A esse respeito Silva, Pontes, Magalhães, Silva e Bichara (2006) encontraram, em Belém, um resultado bastante revelador da conduta de meninos e meninas em relação à segregação: a significativa penetração das meninas nos grupos de meninos e em suas brincadeiras. Esses autores argumentam que a penetração das meninas no espaço masculino não se dá apenas pela pouca disponibilidade de parceiros (elas mesmas poderiam se segregar em grupos menores), mas sim por resistência e pressão das meninas que invadem e se apropriam da cultura masculina, diminuindo a distância entre os dois gêneros. A partir dessa constatação Silva e cols. (2006) propõem a hipótese de aproximação unilateral, ou seja, só um dos lados busca a aproximação. Não se registrou nenhum evento onde meninos buscassem penetrar num grupo formado por meninas. Os autores esclarecem que essa é outra possibilidade de explicação do fenômeno da segregação em acréscimo à hipótese apontada por Martim e Fabes (2001) de que a segregação ocorre a partir de dois padrões: um denominado de polarização dual, no qual os comportamentos dos dois grupos se distanciariam a partir de um ponto inicial em direções opostas, e o outro denominado de polarização singular onde os comportamentos de apenas um dos dois sexos mudariam através dos tempos, enquanto o outro permaneceria estável.

A segregação em grupos do mesmo gênero por si só não contém a única barreira que limita a aproximação do outro grupo. A tipificação e estereotipia na escolha dos brinquedos e nas brincadeiras são outros recursos de que dispõem as crianças para reforçar as suas peculiaridades enquanto grupo. Diversas pesquisas têm constatado que meninos e meninas variam quanto à forma de se organizar social e espacialmente: meninos engajam-se em grupos mais amplos de amizade, utilizam mais tentativas de dominação, ocupam mais espaços abertos e amplos para brincar, enquanto as meninas participam de grupos menores, em ambientes fechados e utilizam mais recursos comunicativos para manter a coesão do grupo (Archer, 1992; Aydt \& Corsaro, 2003). Estudos têm identificado também maior estereotipia entre meninos do que entre meninas, bem como maior reação para com o parceiro que se comporta de maneira inadequada segundo as expectativas do grupo (Bichara, 1994). A rigidez dos padrões masculinos nas brincadeiras pode estar associada à própria desvalorização que a sociedade atribui ao papel da mulher, sugerindo que a feminilidade é um aspecto a ser evitado, devido ao seu menor status (Bichara \& Carvalho, 2008).

Considerando que a maioria dos estudos que investiga a relação brincadeira e gênero foi realizada em espaços restritos como creches e escolas, faz-se importante uma maior investigação sobre os fenômenos associados a gênero em ambientes onde as crianças se organizem livremente para brincar e disponham de espaços amplos para tal. Os 'parquinhos' públicos localizados em praças, parques e jardins das grandes cidades apresentam algumas peculiaridades que justificam um olhar sobre como os fenômenos relacionados à organização de meninos e meninas para brincar acontece. Primeiramente se verifica que são bastante atrativos para crianças e considerados pelos adultos como local adequado para se levar crianças pequenas para brincar; segundo, a maioria está localizada em lugares de grande movimentação e neles as crianças são geralmente conduzidas por adultos que determinam o tempo de permanência e supervisionam suas atividades. Por isso, nesses 'parquinhos', que são ambientes abertos nos quais as crianças podem se organizar livremente, a supervisão dos pais frequentemente interfere nessa liberdade.

A partir destas constatações questionamos se crianças, sem conhecimento prévio, ao se encontrarem em um espaço público repetem esses padrões de segregação e estereotipia, ou tendem a brincar sozinhas? As dimensões do parquinho, qualidade dos equipamentos, quantidade de crianças presentes, sítio específico da brincadeira, entre outros, são variáveis relevantes para a formação ou não de grupos de brinquedos? Assim, o presente estudo investigou, através da observação de eventos de brincadeiras, em dois 'parquinhos' de Salvador, Bahia, Brasil, as características das brincadeiras, do uso do espaço, da organização grupal, entre outros aspectos, que possam de alguma forma estar associados a diferenças entre meninos e meninas no uso do espaço público, objetivando esclarecer se os fenômenos comumente encontrados tanto nos estudos realizados em ambientes restritos, quanto em ruas, ou outros locais onde as crianças se organizam livremente para brincar, como estereotipia, segregação, uso diferenciado do espaço, entre outros, estão também presentes.

\section{MÉTODO}

Participantes: Os participantes desta pesquisa foram meninos e meninas, com idade entre quatro e dez anos, escolhidos aleatoriamente, e que se encontravam 
brincando, sem a interferência de adultos, em dois parques públicos de Salvador: o Playground-8 do Parque do Dique do Tororó e o Parque da Praça Dois de Julho (conhecido como Campo Grande).

Situação: A Praça Dois de Julho (Campo Grande) e o Dique do Tororó foram escolhidos por não se situarem numa comunidade específica, ou seja, as crianças que ali vão brincar são oriundas de diferentes regiões da cidade e não se conhecem. Isso permitiu que dados sobre a organização dos grupos não sofressem interferência de outras variáveis que não as restritas ao contexto observado. Também os dois parquinhos, apesar de características gerais comuns, possuem dimensões diferenciadas, o que poderia interferir favorecendo ou dificultando a formação dos grupos e o surgimento de brincadeiras. Também foram escolhidos por consistirem em espaços abertos, públicos e por possuírem equipamentos para crianças. Ambos são importantes áreas de lazer para a população, sendo frequentados por pessoas das mais variadas faixas etárias e classes sociais e estão localizados em áreas centrais da cidade e com grande importância histórica. O estado de conservação geral das praças e dos equipamentos é bom. No entanto, os parques diferem entre si quanto ao contexto social do entorno sendo no Campo Grande formado por bairros e avenidas onde residem pessoas de classe média enquanto no Dique o entorno é formado por bairros de classe média baixa e invasões; ao tamanho, sendo no Campo Grande a área do parque mais ampla possibilitando a realização de brincadeiras fora dos aparelhos, enquanto no Dique a área do parque é bastante restrita não havendo muito espaço para outras atividades; a quantidade de recursos disponíveis e ao número e qualidade dos equipamentos, havendo mais e melhores recursos no Campo Grande.

O Parque do Campo Grande possui uma área extensa e arborizada, sendo normalmente frequentado por moradores dos bairros circunvizinhos, "meninos de rua" e crianças ali levadas por adultos. O local delimitado para a brincadeira diferencia-se do restante da praça por possuir grama sintética e ser rodeado por bancos de madeira e área ajardinada. $\mathrm{Na}$ área delimitada para a observação são encontrados seis equipamentos em formato de bichos (um rinoceronte, um elefante, uma aranha, uma girafa, um cavalo e um jacaré), outro central multifuncional, uma casinha, também multifuncional, e duas barras. Todos os equipamentos são confeccionados em madeira e ferro e fixados ao solo. A Figura 1 mostra crianças brincando nesses equipamentos. $\mathrm{O}$ parque possui ainda em anexo, um "rinque" oval revestido de cimento.

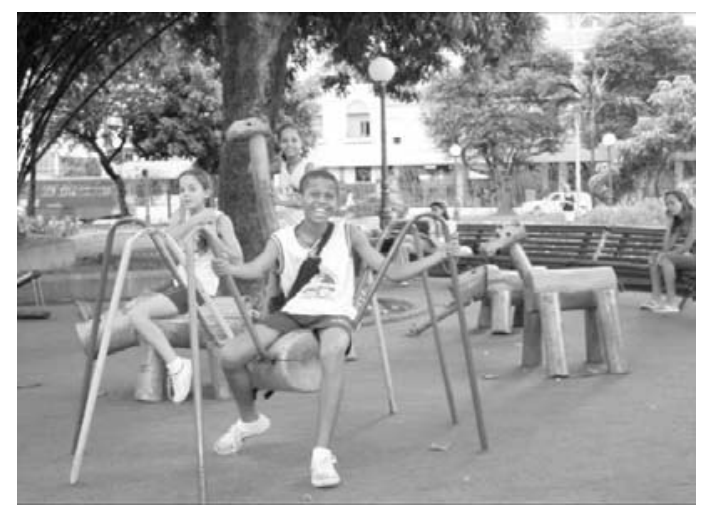

Figura 1. Crianças brincando nos equipamentos do Campo Grande.

O Playground - 8 do Dique do Tororó ocupa uma área de aproximadamente 40 metros quadrados coberta por areia, onde estão fixados, lado a lado, três módulos de equipamentos infantis multifuncionais. Os três equipamentos possuem escorregadores, peças móveis, escadas e mastros, que são constituídos por estruturas de material plástico colorido e metal. Cada módulo de equipamento possui características diferentes, que parecem obedecer a uma ordem de complexidade, assim, denominamos de ap1 ao aparelho maior e com mais recursos disponíveis, de ap2 ao intermediário e de ap3 o aparelho menor e mais simples. O parque é delimitado, pelo guarda-corpo que margeia a lagoa e, do lado oposto, por uma calçada, onde muitas pessoas caminham ou fazem cooper. $\mathrm{O}$ local é predominantemente freqüentado por crianças acompanhadas por adultos. A figura 2 mostra a disposição dos equipamentos do referido parquinho e seu entorno. 


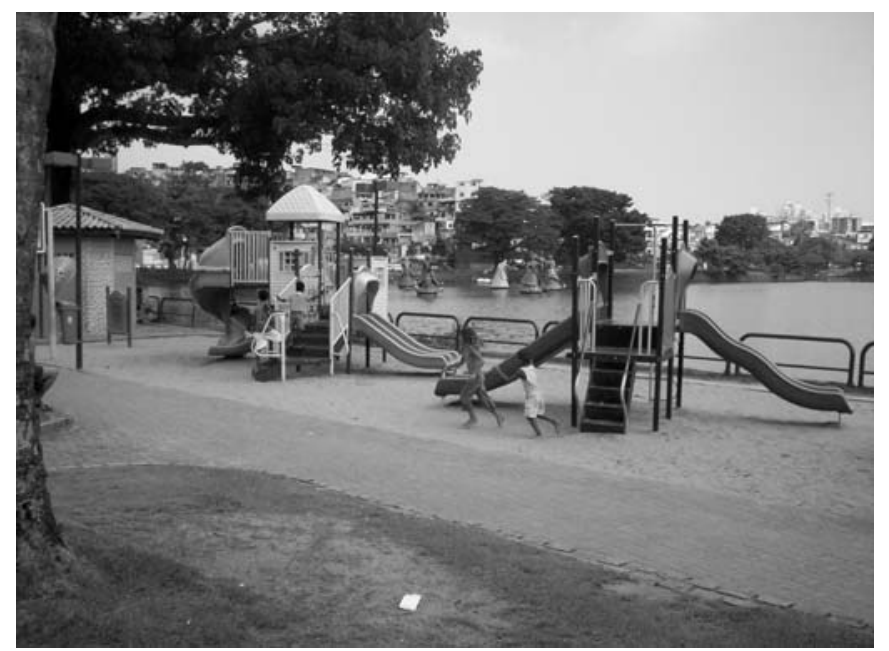

Figura 2. Vista geral do playground 8 do Dique do Tororó e seu entorno.

\section{Procedimentos}

A coleta de dados foi realizada através de observação direta do comportamento em ambiente natural, em sessões semanais com duração de 1 hora, utilizando-se duas técnicas complementares: registro cursivo focal do evento de brincadeira com duração de 5 minutos através do qual eram descritas as ações e interações na brincadeira - e observação em varredura (scan) (Altman, 1974), que consistia em marcar, a intervalos de 5 minutos, a localização das crianças, diferenciando-as por gênero, em uma folha com a reprodução da configuração do espaço observado. Com o objetivo de garantir maior fidedignidade, os registros foram realizados por dois observadores. Ao todo foram realizadas 22 sessões no Campo Grande e 25 no Dique. Os observadores, localizados em pontos onde obtinham visão ampla do parquinho, escolhiam aleatoriamente uma criança ou um grupo que estivesse brincando e passavam a descrever a brincadeira durante cinco minutos. Ao fim do registro realizavam a varredura que durava aproximadamente um minuto e em seguida passavam a observar outra brincadeira. Assim, em cada sessão de uma hora, eram realizados, em média, 10 registros cursivos e 10 varreduras.

\section{Análise dos dados}

Os dados do scan foram empregados a fim de permitir uma análise da presença e da movimentação das crianças no espaço disponível e as frequências por equipamentos ou sítios, de acordo com o gênero. Já os dados do registro cursivo permitiram análises tanto quantitativas quanto qualitativas dos eventos de brincadeiras. Estes dados foram dispostos em planilhas, categorizados e relacionados com diversas variáveis, tais como gênero, local de ocorrência do evento e formas de interação.

Como, nesses dois parques, crianças chegam e saem frequentemente, os dados relativos à presença de crianças, obtidos através do scan, não podem ser absolutizados, por isso sempre nos referimos a um número estimado de crianças. As idades das crianças também foram estimadas, por essa razão não foram utilizadas como variável.

\section{Questões éticas}

O presente projeto foi submetido e aprovado pelo Comitê de Ética da Faculdade de Filosofia e Ciências Humanas da UFBA com isenção de consentimento informado baseado na Resolução 016 do CFP de 20 de dezembro de 2000 que prevê, no Artigo $6^{\circ}$, que o psicólogo pesquisador poderá estar desobrigado do consentimento informado em situações que envolvem observações naturalísticas em ambientes públicos em que não há risco de violar a privacidade dos indivíduos envolvidos nem de causar a eles ou aos grupos e comunidades aos quais pertencem, qualquer tipo de constrangimento.

\section{RESULTADOS E DISCUSSÃO}

Iniciamos a análise dos resultados pelo levantamento sobre a presença de meninos e meninas nos dois parques a fim de verificar se havia, como em outros estudos, preferências dos meninos por permanecer em espaços abertos (Harper \& Sanders, 1975; Levy \& cols., 1995). Para tal levantamento utilizamos apenas os dados obtidos com o scan. Encontramos 
que no Dique, de um total estimado de 158 crianças, $46 \%$ eram meninos e $54 \%$ meninas, enquanto no Campo Grande, de 264 crianças, 51\% eram meninos e $49 \%$ meninas.

Esse resultado, aparentemente destoante de outros relatados na literatura, pela presença equivalente de meninos e meninas nos parques, pode ser explicado pela presença majoritária de crianças levadas ao local por adultos, já que a faixa etária predominante é de até sete anos de idade e pela localização dos parques entre avenidas com grande movimento de veículos. Esse tipo de frequência difere daqueles onde a presença de crianças é espontânea, nos quais fatores culturais podem interferir na participação, principalmente, das meninas.

Silva e cols. (2006) constataram através de amplo estudo nas ruas de Belém, que a presença de meninas estava associada à idade: à medida que aumentava a idade diminuía o número de meninas presentes. A pesquisa, que contou com sujeitos numa faixa etária de 1 a 18 anos de idade, mostrou que meninas entre quatro e seis anos parecem dispor da mesma oportunidade para brincar na rua que os meninos. Após essa faixa, e marcadamente a partir dos 13 anos, pôde ser visto um maior "recolhimento" das meninas às suas casas tanto pelo maior envolvimento com trabalhos domésticos como pela crença popular de que a rua é mais perigosa para as meninas.

Passamos em seguida ao exame de como essas meninas e meninos se envolveram nas brincadeiras, se estavam sós ou em grupo e se esses grupos eram mistos ou segregados por sexo. Para tal utilizamos os dados obtidos através dos registros cursivos, os quais foram organizados e classificados em categorias a partir de uma adaptação que fizemos nas categorias de interação criadas por Parten (1932), brincadeira solitária, brincadeira paralela, brincadeira associativa e brincadeira cooperativa, que para fins desse trabalho foram agrupadas em 'solitárias/paralelas' e 'em grupos'.

A categoria solitárias/paralelas incluiu os eventos em que as crianças brincaram sozinhas, sendo solitárias aquelas em que as crianças brincavam cada uma de uma brincadeira diferente sem contato umas com as outras, e paralelas quando duas ou mais crianças brincaram sós, no mesmo ambiente, da mesma brincadeira e mantinham contato visual eventual (Howes \& Matheson, 1992). Já os eventos em grupo foram aqueles em que duas ou mais crianças brincaram da mesma brincadeira associando-se ou cooperando umas com as outras, podendo formar grupos só de meninas, só de meninos ou mistos. A Tabela 1 mostra a distribuição dos percentuais da participação dos grupos de meninos, meninas e mistos nas brincadeiras através das categorias solitárias/paralelas e em grupos nos dois locais, assim como os valores do Quiquadrado, grau de liberdade e probabilidade associada (p) para cada categoria de interação em relação ao gênero dos brincantes.

TABELA 1

Frequência (\%), Valor do Qui-quadrado, Valor de $p$ e Grau de Liberdade para o Tipo de Interação na Brincadeira em Cada Local Conforme o Gênero do Grupo de Crianças

\begin{tabular}{cccccc}
\hline & \multicolumn{2}{c}{ Dique } & & \multicolumn{2}{c}{ Campo Grande } \\
\cline { 2 - 3 } \cline { 5 - 6 } Gênero do grupo & Solitária/Paralela & Grupo & & Solitária/Paralela & Grupo \\
& $\mathrm{N}=124$ & $\mathrm{~N}=202$ & & $\mathrm{~N}=444$ & $\mathrm{~N}=140$ \\
\hline Masculino & 29,03 & 18,32 & & 47,52 & 30,71 \\
Feminino & 54,84 & 23,76 & & 44,37 & 34,29 \\
Misto & $16,13^{*}$ & 57,92 & & $8,11^{*}$ & 35 \\
$\chi^{2}$ & 28,90 & 55,85 & & 127,80 & 0,44 \\
$p$ & $<0,001$ & $<0,001$ & & $<0,001$ & $<0,801$ \\
gl & 2 & 2 & & 2 & 2 \\
\hline
\end{tabular}

Nota: *Dados relativos apenas às brincadeiras paralelas. 
Como pode ser visto na Tabela 1 , os resultados indicam que podemos aceitar que existe uma diferença significativa entre os grupos de meninas, meninos e mistos para as brincadeiras solitárias/paralelas nos dois locais ( $\mathrm{p}<0,001 \mathrm{em}$ ambos) e para as brincadeiras em grupo no Dique $(\mathrm{p}<0,001)$. Entretanto, para as brincadeiras em grupo no Campo Grande não foi encontrada diferença significativa $(\mathrm{p}=0,801)$, ou seja, para este tipo de interação nas brincadeiras não houve diferença quanto a composição dos grupos, se formados apenas por meninas, por meninos ou mistos. Quanto às frequências, observamos que, no Dique, a maioria das brincadeiras solitárias/paralelas foi desenvolvida pelas meninas $(54,84 \%)$ e as em grupo ocorreram principalmente nos grupos mistos (57,92\%).

Estes resultados nos mostram que embora as meninas tenham brincado mais que os meninos de forma solitária ou paralela no Dique, esta mesma tendência não foi vista no Campo Grande (aonde estas formas de interação mostraram-se próximas entre os dois gêneros). É possível que outros fatores, como influências do contexto, por exemplo, possam estar associados a esta diferença entre os dois locais. É preciso também avaliar a influência de outros fatores, além do gênero, para analisar porque se encontrou, diferentemente do relatado em outros estudos (Martim \& Fabes, 2001; Silva \& cols., 2006; entre outros), pouca segregação entre os gêneros nos grupos de brinquedo. Aqui também a explicação mais plausível parece ser a mesma que apresentamos para a diferença entre os dois locais sobre as brincadeiras solitárias e paralelas: é possível que aspectos contextuais apresentem-se como influências mais marcantes nas interações infantis neste tipo de local. Ou seja, estamos falando aqui de crianças levadas por adultos e não de crianças que foram espontaneamente para ali brincar, o que pode mudar a forma de organização. Para tentar esclarecer estas questões passamos ao exame dos episódios de brincadeiras, suas formas, tipos, equipamentos envolvidos etc.

\section{As brincadeiras:}

Ao todo foram registrados 910 episódios de brincadeiras, sendo que destes, 326 ocorreram no Dique do Tororó e 584 no Campo Grande. Para melhor compreensão sobre o conteúdo e forma dessas brincadeiras, os eventos registrados foram organizados a partir da classificação proposta por Moraes e Otta (2003), que adaptaram e ampliaram as categorias contidas em Piaget (1945/1971) e Parker (1984) e que assim podem ser descritas: 1) Brincadeiras de Exercício Físico: brincadeiras nas quais as crianças exercitam um número variado de comportamentos "com vigor físico", como Subir e descer dos equipamentos; 2) Brincadeiras de Contingência Social: põem em ação o esquema de revezamento social como, por exemplo, Carregar no colo, Cantar/Dançar; 3) Brincadeiras de Construção: como o próprio nome já diz, são brincadeiras nas quais os materiais disponíveis são combinados para a criação de um outro, como por exemplo, as brincadeiras utilizando areia; 4) Brincadeiras Turbulentas: nestas brincadeiras as crianças enfrentam algum "perigo" ou testam seus limites, quer sejam eles físicos ou sociais, através da exibição de movimentos bruscos, semelhantes aos da situação real, mas que diferem pelo seu caráter lúdico expresso na face típica de brincadeira tanto do brincante quanto do oponente atacado (Wanderlind \& cols., 2006). Deste tipo foram registradas brincadeiras de Equilibrar-se/usar partes instáveis dos equipamentos, Puxar/empurrar/segurar o outro; 5) Brincadeiras de Faz-de-Conta: são as brincadeiras simbólicas, imaginativas, nas quais as crianças atribuem aos objetos, a si e aos outros, papéis diferentes dos habituais, por exemplo, casinha, cavalo etc.; 6) Brincadeiras com regras: são as que envolvem regras, estrutura e papéis pré-definidos que norteiam o desenvolvimento do brinquedo, como Pega-pega, Bola, Jogo da velha e Esconde-esconde.

A Tabela 2 mostra a distribuição dos eventos observados para cada uma destas categorias, de acordo com a composição do grupo de brinquedo em cada parque. Como pode ser visto a categoria mais frequente, para todas as formas de composição dos grupos de brincantes, foi aquela classificada como de exercício físico. Estes eventos consistiram, em sua maioria, em subir e descer dos equipamentos, sendo essas atividades muito parecidas nos dois parques. Como neste tipo de ambiente a maioria das crianças não possui conhecimento prévio, os equipamentos além de exercerem grande atração sobre elas, podem funcionar como mediadores de interações. 
TABELA 2

Frequência de Cada Tipo de Brincadeira Conforme o Gênero dos Participantes, por Parque

\begin{tabular}{lcccccccc}
\hline Categorias & \multicolumn{3}{c}{ Dique } & & \multicolumn{3}{c}{ Campo Grande } \\
\cline { 2 - 4 } \cline { 6 - 8 } & $\mathrm{M}$ & $\mathrm{F}$ & $\mathrm{MF}$ & & $\mathrm{M}$ & $\mathrm{F}$ & $\mathrm{MF}$ \\
\hline Faz-de-conta & - & 5 & 5 & & 22 & 20 & 3 \\
Jogo de regra & 11 & 12 & 24 & & 15 & 9 & 21 \\
Construção & 3 & 16 & 2 & & - & - & - \\
Turbulenta & 5 & 9 & 8 & & 7 & 5 & - \\
Contingência social & 3 & 7 & 2 & & 2 & 1 & 2 \\
Exercício físico & 51 & 64 & 95 & & 203 & 207 & 56 \\
Outras & 1 & 3 & - & & 5 & 3 & 3 \\
\hline $\mathrm{N}$ & 74 & 116 & 136 & & 254 & 245 & 85 \\
\hline
\end{tabular}

A maior frequência das brincadeiras de exercício físico corrobora a visão predominante de que esse tipo de espaço estimula a realização de brincadeiras voltadas à promoção do desenvolvimento de habilidades físicas conforme encontrado em Johnson, Christie e Yawkey (1999). Não obstante, um olhar mais atento pode evidenciar que pode ser simplista essa constatação e que outros ângulos devem ser investigados. É o que vamos buscar através da análise de variados fatores envolvidos nestas atividades.

\section{Brincadeiras de exercício físico:}

Dentre as 210 brincadeiras classificadas como exercício físico registradas no Dique e 466 no Campo Grande, aproximadamente $94 \%$ e $88 \%$, respectivamente, envolveram os equipamentos dos parques. $\mathrm{Ou}$ seja, de forma mais frequente as crianças subiam e desciam dos aparelhos utilizando os diversos recursos como escorregadores, escadas, mastros e plataformas. Percebeu-se que no Dique esta atividade apresentou maior diversidade nas formas de utilização dos mesmos. Assim, as crianças, muitas vezes, iniciavam o que parecia ser uma exploração dos três módulos dos equipamentos e, logo em seguida, passavam a fazer suas apropriações específicas do espaço, com alguns usos até inusitados, como no seguinte evento:

(...) uma menina com cerca de três anos, sobe a escada menor do aparelho três e desce a escada maior como se fosse um escorregador. Ela sobe a escada, senta-se e desliza sobre a escada lentamente. Retira a areia do último degrau da escada, sobe novamente e senta-se. Um menino de aproximadamente seis anos, sobe no aparelho três e a menina desce as escadas de pé (não mais como um escorregador). O menino desce a escada escorregando (como a menina havia feito antes). A menina sobe novamente e desce a escada escorregando sentada; uma outra menina, com cerca de cinco anos, senta-se atrás dela e também desce a escada como um escorregador (...).

A partir deste evento é possível observar, portanto, que as crianças fazem adaptações ao ambiente mesmo quando este parece estar direcionado para uma dada atividade. Entretanto, não é possível deixar de pensar na influência da conformação do espaço e dos recursos disponíveis sobre as escolhas das crianças no que concerne aos tipos de brincadeiras observadas.

Examinando separadamente os episódios de brincadeiras de exercício físico, constatamos que no Dique, os grupos mistos envolveram-se mais nesse tipo de brincadeiras ( $45 \%$ do total para esse local), enquanto que no Campo Grande foram os grupos segregados ou crianças isoladas (44\% para meninos e meninas igualmente) que apresentaram as frequências maiores.

No Campo Grande podemos ver que, proporcionalmente, as brincadeiras de exercício físico concorreram com os jogos de regras (vide Tabela 2), nos grupos mistos, o que pode indicar maior complexidade na formação desses grupos, visto que brincadeiras com regras implicam no acatamento coletivo das mesmas, negociações sobre papéis, liderança etc. Foram mais frequentes pega-pegas e jogos com bolas. Pudemos constatar também no Campo Grande algumas diferenças na ocupação do espaço relacionadas ao gênero: meninas se concentraram nos equipamentos, enquanto os meninos utilizaram em grande proporção a área livre do rinque. Esta constatação é semelhante a, também, encontrada por Karsten (2003), que argumenta que algumas vezes as áreas de um playground podem ser definidas por gênero, onde meninas ocupam áreas restritas ou alguns brinquedos, enquanto meninos distribuem-se por todo o espaço. Essa mesma preferência, de meninas por espaços internos e/ou restritos e de meninos por áreas externas e amplas, como cita- 
do anteriormente, também foi constatada em outros estudos parecendo se constituir numa diferença de estilos associada ao gênero (Bichara \& Carvalho, 2008).

Já no Dique, a distribuição das crianças no espaço não apresentou diferenças marcantes quanto ao gênero. Neste parque, o aparelho 1 exerceu maior atração nas crianças, de ambos os sexos, que o utilizaram com frequência superior aos outros equipamentos. É importante ressaltar que nesse parquinho as crianças não tinham muitas opções de escolha entre áreas amplas ou restritas já que o espaço disponível é muito limitado.

\section{Faz-de-conta e jogos com regras:}

Mesmo ocorrendo em menor frequência, as brincadeiras de faz-de-conta e os jogos com regras merecem destaque, pois são brincadeiras com maior grau de complexidade de conteúdo e forma. Os jogos com regras foram brincados em ambos os parques por meninos e meninas, sendo mais frequente entre os grupos mistos do Campo Grande. A descrição a seguir de um evento de pega-pega é exemplar do tipo de brincadeira observada neste local:

Menino $V$. procurando o outro escondido atrás dos bancos. Diz: "Bora brincar de pega-pega por aqui, se eu te pegar sou o campeão. Bora! 1, 2, 3, já!”, e saem correndo. Os dois correm em volta do rinque. V. tenta pegar A. e o alcança na casinha. A. diz: "Picula" e simula estar cansado, se abanando. A. se pendura e $V$., que tentava fugir dele, cai na grama. A. diz estar cansado e fala: "Dois altos!". A. finge chorar e segura a cabeça, fingindo sentir dor, em seguida fala "Te peguei!" para V".

As brincadeiras de faz-de-conta envolveram temas de casinha, imitar bichos e barco. No Dique, o tema "casinha", presente em grupos femininos e mistos, surgia, de maneira geral, em meio às brincadeiras de subir e descer dos aparelhos, onde cada módulo costumeiramente era identificado como uma casa. Os eventos descritos a seguir, ilustram este fato:

A menina A. diz que cada aparelho é uma casa - ap1 de A., ap2 de V. e ap3 de E (4 anos). A diz "Cada uma na sua casa". Sobem cada uma num aparelho. A. (7 anos) no caracol conversa com V. (7 anos). Descem o caracol. Ela diz "A sua (casa - ap 1) é mais bonita". Cada uma fica em um aparelho. A diz para E. "Vem E. morar aqui (ap1)...".

Menina $V$. sobe a escorregadeira e senta-se na parede do aparelho 1. Grita: "Jaqueline!". O menino diz: "So- corro! Eu não sei nadar!'. A menina $V$. desce a escorregadeira dupla, sobe a escada e diz: "Já vai! A salvavidas salva". Menino grita socorro, ela desce o caracol gritando, pára no menino que está deitado na frente e diz: "A água está entrando!”. Ela sobe o caracol de pé. Chama a outra menina: "Jackie", se pendura na escadinha. Jaqueline diz que já consertou o barco e que ela pode descer. Ela sai do apl junto com a menina e diz: "Consegui!" Vira-se para o menino e fala: "Se afoga, Bruno!". Jaqueline pula em cima do ap1. Desce correndo as escadas e vai para o ap3, entra, retorna ao ap1, onde está o menino. Diz para o menino: "Desce!", ele responde: "Eu não sei nadar". Ela escorrega o caracol, sobe a escadinha, desce pela escada e chama a menina de vermelho: "Vambora", o menino fica no caracol e diz: "Me esperem!". Ela sai com a menina e, em seguida o menino as segue para fora do parque.

Os exemplos encenados por um grupo feminino e por um grupo misto, respectivamente, ilustram temas que têm relação com a tipificação por gênero, um tema doméstico, comum em brincadeiras femininas, e um tema mais próximo de profissão/fantástico, frequentemente observado em brincadeiras de faz-deconta masculinas.

É interessante notar, nos exemplos citados, que as crianças envolvidas nesses episódios ou já se conheciam anteriormente ou desenvolveram estratégias de aproximação e interação no próprio parque, o que abre um novo campo de investigação acerca das interações para brincar em ambientes públicos. De qualquer forma, os resultados apresentados já mostram o quão ricas podem ser essas interações e o quanto de variabilidade em formas de brincar pode conter um aparentemente simples subir e descer de equipamentos.

\section{CONCLUSÕES}

Pudemos constatar nesse estudo alguns fenômenos interessantes relacionados ao espaço em si e ao fato das crianças serem pequenas e não se conhecerem: a tendência a brincarem solitariamente, pelo menos nos primeiros minutos de permanência no local; que essa brincadeira se concentra nos aparelhos e se caracteriza como de exercício físico (subir, descer, escorregar); a buscar a aproximação das outras crianças para brincarem junto em grupos, segregados ou não; a brincar mais de brincadeiras de faz-de-conta e com regras na existência de espaço mais amplos; havendo opção, as meninas brincam mais nos aparelhos e espaços mais restritos enquanto os meninos ocupam áreas maiores.

Os fenômenos associados a diferenças entre meninos e meninas aparecem, mas não são tão determi- 
nantes quantos aqueles advindos de pesquisas com crianças mais velhas e em ambientes como escolas, ruas e outros espaços próximos as suas casas. Conhecimento prévio parece ser então, uma variável importante na formação de grupos segregados e no estabelecimento de estilos diferenciados de brincar conforme o gênero (Aydt \&Corsaro, 2003). Porém, os resultados aqui relatados referem-se a um tipo de ambiente específico que tem representado um importante recurso para a socialização infantil, sobretudo, nas grandes cidades. Muitos fenômenos associados ao brincar em parquinhos e outros espaços públicos em grandes cidades ainda precisam ser mais investigados, por grupos diversos para, inclusive, subsidiar políticas públicas relacionadas ao planejamento urbano que leve em consideração as necessidades infantis em todos os espaços das cidades.

\section{REFERÊNCIAS}

Altman, J. (1974). Observational study of behavior sampling methods. Behavior, 49, 227-267.

Archer, J. (1992). Childhood gender roles: Social context and organisation. Em M. McGurk (Org.), Childhood social development: Contemporary perspectives (pp. 31-61). Hillsdale: Lawrence Erlbaum.

Aydt, H., \& Corsaro, W. A. (2003). Differences in children's construction of gender across culture an interpretive approach. American Behavioral Scientist, 46(10), 1306-1325.

Beraldo, K. E. A. (1993). A percepção de crianças de 5 a 10 anos em relação a diferenças de gênero de brincadeiras. Dissertação de mestrado não-publicada, Universidade de São Paulo.

Bichara, I. D. (1994). Um estudo etológico sobre a brincadeira de faz-de-conta em crianças de 3 a 7 anos. Tese de doutorado não-publicada, Universidade de São Paulo.

Bichara, I. D. (2003). Nas águas do Velho Chico. Em A. M. A. Carvalho, C. M. C. Magalhães, F. A. R. Pontes \& I. D. Bichara (Orgs.), Brincadeira e cultura: Viajando pelo Brasil que brinca (pp. 89-108). São Paulo: Casa do Psicólogo.

Bichara, I. D., \& Carvalho, A. M. A. (2008). Gênero e brincadeira: Parcerias e preferências lúdicas. Em V. R. S. Cavalcanti (Orgs.) Gênero: Um olhar interdisciplinar (pp. 50-60). Salvador: Roma Negra.

Gosso, Y., Otta, E., Moraes, M. L. S., Ribeiro, F. J. L., \& Bussab, V. S. R. (2005). Play in hunter-gatherer society. Em A. D. Pellegrini \& P. K. Smith (Orgs.), The nature of play (pp. 213253). New York: Guilford Press.

Gosso, Y., Morais, M. L. S., \& Otta, E. (2006). Pivôs utilizados nas brincadeiras de faz-de-conta de crianças brasileiras de cinco grupos culturais. Estudos de Psicologia, 11(1), 17-24.
Harper, L., \& Sanders, K. (1975). Preschool children's use of space: Sex differences in outdoor play. Developmental Psychology, 11, 119.

Henninger, M. L. (1993). Enriching the outdoor play experience. Childhood Education, 70(2), 87-91.

Johnson, J. E., Christie, J. F., \& Yawkey, T. D. (1999). Play and early childhood development. New York: Longman.

Karsten, L. (2003). Children's use of public space: The gendered world of the playground. Childhood, 10(4), 457-472.

Levy, G. D., Taylor, M. G., \& Gelman, S. A. (1995). Traditional and evaluative aspects of flexibility in gender roles, social conventions, moral rules, and physical laws. Child Development, 66, 515-531.

Maccoby, E. E. (1989). Gender and relationships: A developmental account. American Psychologist, 45(4), 513-520.

Martin, C., \& Fabes, R. (2001). The stability and consequences of young children's same-sex peer interactions. Developmental Psychology, 37(3), 431-446.

Meneghini, R., \& Campos-de-Carvalho, M. I. (2003). Arranjo espacial na creche: Espaços para interagir, brincar isoladamente, dirigir-se socialmente e observar o outro. Psicologia: Reflexão e Crítica, 16(2), 367-378.

Moraes, M. S., \& Otta, E. (2003). Entre a serra e o mar. Em A. M. A. Carvalho, C. M. C. Magalhães, F. A. R. Pontes \& I. D. Bichara (Orgs.), Brincadeira e cultura: Viajando pelo Brasil que brinca: Vol. 2 (pp. 127-156). São Paulo: Casa do Psicólogo.

Poulin-Dubois, D., Serbin, L. A., Kenyon, B., \& Derbyshire, A. (1994). Infants' intermodal knowledge about gender. Developmental Psychology, 30, 436-442.

Pellegrini, A. D. (2004). Sexual segregation in childhood: A review of evidence for two hypotheses. Animal Behaviour, 68, 435-443.

Parker, S. T. (1984). Playing for keeps: An evolutionary perspective on human games. Em P. K. Smith (Org.), Play in animals and humans (pp. 271-293). Oxford: Basil Blackwell.

Parten, M. B. (1932). Social participation among pre-school children. Journal of Abnormal and Social Psychology, 27(3), 243269.

Piaget, J. (1971). A formação do símbolo na criança (A. Cabral, Trad.). Rio de Janeiro: Zahar. (Original publicado em 1945)

Rasmussen, K. (2004). Places for children - Children's places. Childhood, 11(2), 155-173.

Santos, A. K. (2005). Um estudo sobre brincadeira e contexto no agreste sergipano. Dissertação de mestrado não-publicada, Universidade Federal da Bahia.

Sager, F., Sperb, T. M., Roazzi, A., \& Martins, F. M. (2003). Avaliação da interação de crianças em pátios de escolas infantis: 
Uma abordagem da psicologia ambiental. Psicologia: Reflexão e Crítica, 6(1), 203-215.

Seixas, A. A. C. (2007). Brincando na Ilha dos Frades. Dissertação de mestrado não-publicada, Universidade Federal da Bahia.

Silva, L. I. C., Pontes, F. A. R., Magalhães, C. M. C., Silva, S. D. B., \& Bichara, I. D. (2006). Diferenças de gênero(s) nos grupos de brincadeira na rua: Elementos para pensar a hipótese de aproximação unilateral. Psicologia: Reflexão \& Crítica, 19(1), 114-121.

Wanderlind, F., Martins, G. D. F., Hansen, J., Macarini, S. M., \& Vieira, M. L. (2006). Diferenças de gênero no brincar de crian- ças pré-escolares e escolares na brinquedoteca. Paidéia, 16(34), 263-273.

Whiting, B. B., \& Edwards, C. P. (1988). Children of different worlds: The formation of social behavior. Cambridge: Harvard University Press.

Nota:

${ }^{1}$ Apoio: CNPq.

\section{Sobre as autoras:}

Carla Silva Fiaes: Mestranda em Psicologia - Universidade Federal da Bahia.

Reginalice de Lima Marques: Mestranda em Psicologia: Universidade Federal da Bahia.

Gabriela Souza Cotrim: Bolsista de Iniciação Científica: Universidade Federal da Bahia.

Ilka Dias Bichara: Professora Associada do Instituto de Psicologia da Universidade Federal da Bahia.

Endereço para correspondência: Universidade Federal da Bahia - PPGPSI - Estrada de São Lázaro, 197 - 40210-730 Salvador - BA. Endereço eletrônico: ilkadb@ufba.br; csfiaes@yahoo.com.br. 